\title{
Attrition in Higher Education: From a Problem to a Wicked Problem or a Pure Case of Economics?
}

\author{
A. Giannakopoulos
}

\begin{abstract}
The problem of attrition in higher education has plagued higher learning institutions for the past 50 years. Governments and institutions around the world and in South Africa having accepted that graduation rates are far from acceptable, have tried to introduce certain interventions that could minimise the impact of attrition. Some progress has been made but so far no real solution has been found, perhaps due to a great number of factors that affect academic success. More than 130 factors have been identified. Although such factors have been accepted to contribute to academic success the problem is that they are not constant. In an area or a country the top 10 could be as much as $90 \%$ different to another area or country. This instability makes the attrition problem as a problem with no solution, a wicked problem. Other known wicked problems could be poverty, climate change, politics, HIV aids, health and there could be many more.

The question that this paper tries to answer is: Is it possible that, at least in South Africa context, free higher education in every sense could be the answer to the attrition problem? Higher education at all costs versus the right of the individual to higher education creates the discourse. The paper argues that higher education is foremost about economics and is not about whether it is a right or a privilege since in both cases it is about economics. And the sustainability of any institution can only be guaranteed through return on investment. Accepting attrition as a wicked problem the paper, using literature review, makes a number of recommendations that could minimize the impact of attrition as there is no ideal solution.
\end{abstract}

Keywords - Attrition, wicked problem, persistence, retention.

\section{INTRODUCTION}

Since the 1980s of [1] to [2] and [3] models of attrition and [4] model for Open Distance Learning (ODL) and variations of those models, attrition remains at higher than acceptable levels [5]. Carr [6] states that attrition rates in an ODL are between $10-20 \%$ higher than traditional universities. Although a great number of factors have been identified that contribute to academic success what has become apparent is that of all the factors identified are not constant and under the same conditions different factors tend to emerge as predictors. Such instability makes it almost impossible to take proper effective preventative actions. Approaching the problem from a pragmatic perspective it is necessary to examine some important variables such as cost

Manuscript received August 29, 2017.

Dr. A. Giannakopoulos is Lecturer of University of South Africa, South Africa (e-mail: gianna@unisa.ac.za). versus investment, right to free higher education versus privilege to higher education, and access versus access with success. In all three cases the common denominator is academic success. If academic success is achieved then money spent on education is an investment, it can be free, if access is accompanied by success. In South Africa due to apartheid, primary and secondary education is still poor especially in Black townships and higher learning institutions have introduced various interventions to try and minimise the impact of such education. Perhaps it is necessary to revisit certain policies of the past which might shed some light on the attrition. The approach though should be one of treating attrition as a wicked problem as [7] did.

\section{ATTRITION: A WICKED PROBLEM?}

The term 'wicked' was first coined by Horst Rittel in the 1970s. It was used to describe problems that are either difficult to solve or do not have a solution (though we might think they have a practical solution but mostly an ideal solution which is ....impractical!). Poverty, education, crime and road deaths (especially in South Africa), economic, environmental and political issues could be considered as wicked problems. Beer and Lawson [7] characterised attrition in education sphere as a wicked problem as it necessitates unorthodox, innovative ways rather than using standard problem solving techniques. Rittel and Webber [8] concentrated only on economic, environmental and political spheres. They identified 10 characteristics of wicket problems which are also evident in attrition:

- There is no definitive formulation of a wicked problem. Attrition in higher education is recognized as a complex human phenomenon [9], [10].

- Wicked problems have no stopping rule. Attrition has been with us for decades and it does not seem to abate in spite of great efforts by researchers around the world. Approaches used should try to improve the situation rather than solve it [7].

- There is no immediate and no ultimate test of a solution to a wicked problem. One has to design approaches as he/ she goes along rather than try to develop a 'one size fits all'.

- Every solution to a wicked problem is a "one-shot operation"; Such solution depends on the designer's perspective.

- Wicked problems do not have an enumerable (or an exhaustively describable) set of potential solutions. The 
inter-connectivity and inter-dependence of the factors of attrition require to identify the factors particular to a setting.

- Every wicked problem is essentially unique. Attrition is a unique phenomenon.

- Every wicked problem can be considered to be a symptom of another problem. In higher education, there is an interdependency between the various factors that contribute to attrition.

- The existence of a discrepancy representing a wicked problem can be explained in numerous ways. Attrition is multi-facet thus it requires a multi-disciplinary way.

- The social planner has no right to be wrong (i.e., planners are liable for the consequences of the actions they generate). Whoever designs a plan to improve attrition, carries also the responsibility of the outcome.

Based on the above exposition, attrition can be considered as a wicked problem. Attrition is associated in simple terms with non-completion of studies. When that happens it leads to wastage. But wastage also occurs when students take longer to complete their studies. With students dropping out for various reasons does not only affect the institution in monetary terms but it can also lower its status [11]. It also affects the student psychologically as feelings of inadequacy, being a failure do affect his self-worth [2]. If a student believes that he/ she can succeed and he/ she fails to graduate it was classified as "academic suicide". Blythman and Orr [12] viewed the dropout as an institutional failure.

\section{A.Stages of Attrition}

Attrition can be said that it starts the moment a prospective student applies to the institution to study some course. In Fig. 1 students are accepted but do not turn up for registration. This group affects the input as there could have been others that were rejected and could have been successful students. Then the First Time Enrolments (FETs) plus students that had failed previously less the students who dropout for different reasons or not allowed to re-register next year/ semester. The same pattern is followed in the following years adding possible stop-outs. Keeping records of the various dropouts and failures is absolutely necessary as that affects the economics although it is difficult to do so [13]. At this point is necessary to revisit what constitutes a dropout in institutional terms, in student's terms and in government terms.

Defining a dropout which leads to wastage is a complex matter. First for an institution or a course if the student does not enroll, even if successful up to that point, next year/ semester, the student is considered as a dropout [2]. And a drop out means loss of income to the institution because another student could have taken that space [11] which remains 'empty' for the duration of the programme [14]. As [11] puts it when a student leaves an institution he/ she takes his money with. From a student's perspective dropping out from a wrong course he/ she chose, or accepting a job offer, or suspending his/ her studies for various reasons (stop-out) is not a drop out. From government perspective if a student changes course or university is also not a drop out. In all three cases it is a matter of completing the studies sooner or later. A dropout will be the one that contributes to students' mortality and wastage. But taking longer to complete the studies also leads to wastage.

\section{BACKGROUND TO ACCESSING HIGHER EDUCATION}

With the massification of higher education in the '90s, rapid growth in technology and globalization, brought also more students to higher education to upgrade their knowledge. It is estimated that there was almost a $100 \%$ increase in student population in some cases within a decade [10],[11]. As a result attrition rates, around the world increased as well as in South Africa after the fall of apartheid in 1994. Accessing higher education varied between minimum requirements (e.g. a Grade 12 certificate) and for highly selective institutions top grades; from open access to restricted access; from being accessed by the elite, the rich and privileged to poor as a human right for higher education as a vehicle to prosperity. The institutions aim at giving access to those that stand a good chance of graduating while the student having a good academic record believes that he/ she will be able to graduate [2]. But both parties are getting it wrong as attrition rates still vary between $10 \%$ in highly selective institutions and $80 \%$ in the rest [9].

Attrition and not graduating within the specified period it leads to wastage of money, time and resources, for all stakeholders. Research done for the past 50 years on reasons of attrition and students taking longer to complete is inconclusive. The main reason being that the 130 [1] plus factors identified vary from region to region, country to country and even within faculties. Thus its wickedness.

With respect to the question whether higher education is a privilege or a right [15] came to the conclusion that it is a matter of perspective. From the institution's perspective, it is a privilege due to limited resources and unless there is a relative high proportion of students that one on the hand graduate in the prescribed period, on the other hand they persist and graduate, the institution cannot sustain itself. From the student's perspective, he/ she has a right to higher education so he/ she can improve his/ her life as research has shown [17] that graduates do earn more money than those without higher education. A higher education qualification also affects their status.

Archer, Leathwood and Hutchings [17] maintain that privilege buys protection from risks while disadvantaged carry the greater threats and risks. But the institution too when it allows a student in to study if the cost to educate the student is considered as an investment and the return on investment (ROI) is low (low graduation rates), it cannot sustain itself. And research has shown that it is the low income group that the debt mostly incurs. 


\section{Attrition model}

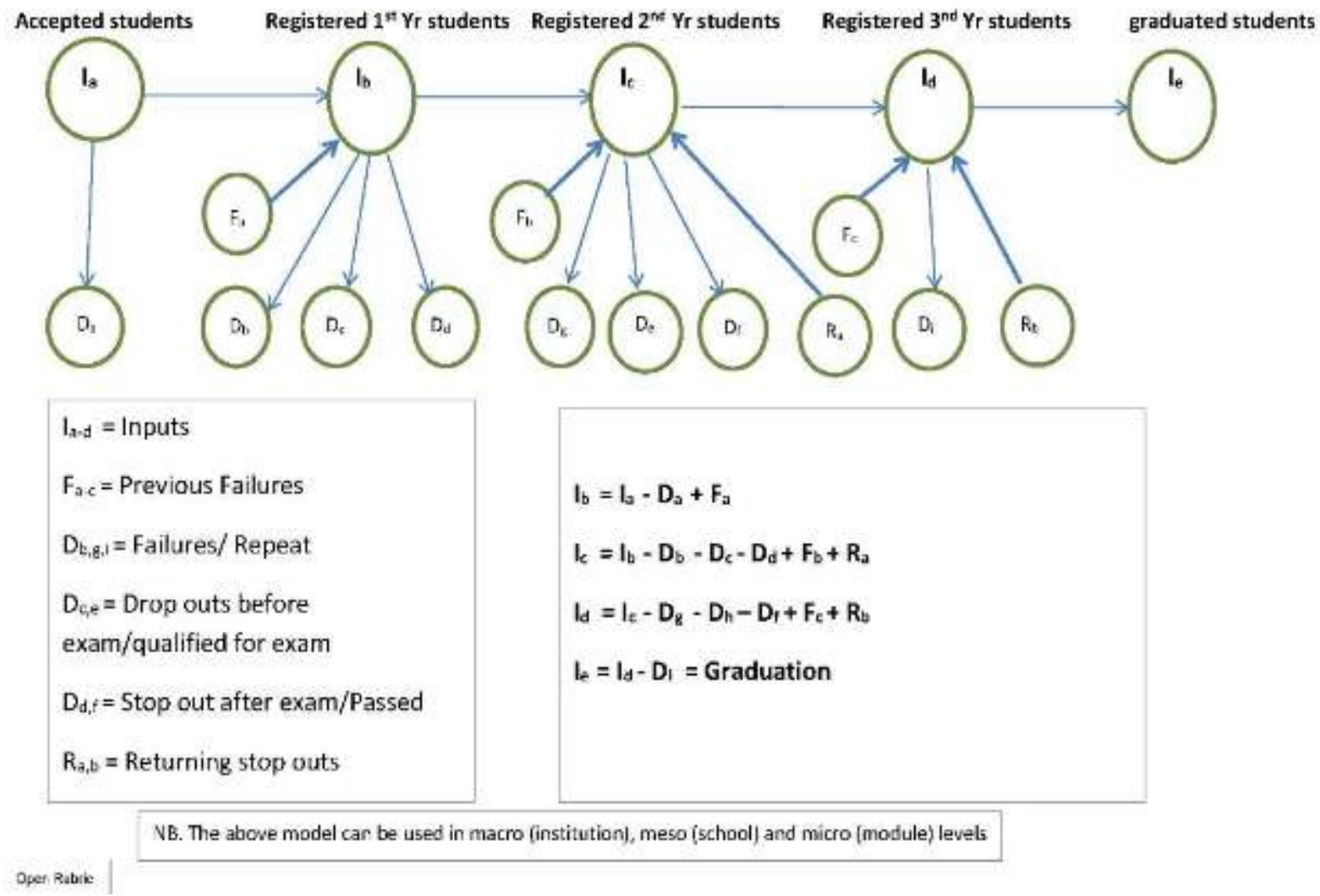

\section{HIGHER EDUCATION AS A RISKY AND EXPENSIVE BUSINESS}

What many may fail to realise is that concentrating on cost to educate the student such a cost does not begin when the student enters the institution, but long before that. The institutions have to advertise themselves to try and attract quality students, having open days, offering career guidance and other means which all cost money. Then the second phase begins when a student is accepted in a course but does not turn up on registration day. The third phase is when a student does register but then withdraws before even classes begin or withdraws during the first week or month of studies. All three phases contain non recoverable cost. Then the fourth phase starts when the student begins to settle in and for various reasons he/ she drops out. This fourth phase is considered as the phase that has the greatest impact on the institution because it is one where the highest attrition occurs. It is a phase where there are only 'losers'; the institution loses income as, had it admitted others, they might not have dropped out [14]; the student incurred some cost and wasted time [2],[5]; the government too and also they might leave behind a debt.

While for the first two phases the institution has not much control in attracting high caliber students and retaining them, in the 3rd and 4th phases it has. The third phase is an intermediate phase where the student has either decided to withdraw in advance or soon after registration for various reasons. Phase two and three require extensive research. The fourth phase has been recognised internationally to be the most critical one and that is when various interventions have been developed. It is a matter between retention (from institutional perspective) and persistence (from a student perspective). Non retention or non-persistence leads to attrition [2]. Retention cannot be at all costs as the longer the student takes to graduate the less the profit and also impacts the status of the institution [12],[18]. One gets what is call in some academic circles students become 'permanent residents'. On the other hand if the student keeps persisting and he/ she does not make sufficient progress he/ she cuts his/ her losses and drops out.

Phase two is where the question of access arises. With access the risk of admitting the student to the institution is at its highest levels. The reason is that as the number of places for each course are limited then choosing a wrong candidate leads to financial loses and had the institution chosen another student he/ she might have graduated as stated earlier. In the South African context, a Grade 12 with exemption certificate is the minimum requirement to enter university. With no exemption the student can attend a college. But different courses could have extra requirements.

What has not been disputed at large is that higher education is a prerequisite to economic growth and sustainability [19]. The more educated a human being is, the higher their income, the greater the innovation, more taxes are collected and this leads to prosperity. At the same time higher education is an expensive and risky business [20] for both the institution and the student. If there is no $100 \%$ success rate it leads to a wastage. 


\section{A. Access, Retention, Persistence and Graduation}

These four constructs are interlinked. Research [13],[21],[22] has shown that once the student begins with his/ her studies and does not dropout in the first semester/ year, effective retention policies (institutional endevour) and a highly motivated student, can lead to persistence and raises the probability of graduation. As a rule retention should aim at increasing the desire in the student to persist, and not at retaining the student at all costs. For Marinez [23], persistence refers to the act of continuing toward an educational goal such as earning a degree or certificate. Retention is measured by the number of students that progress from one level to next in a degree program until either completion of the degree programme or the student's personal goals are met [24].

Tinto [21] identified three main factors that contribute to student motivation to persist: Self-efficacy, sense of belonging and perceived value of the curriculum. "Self-efficacy refers to a person's belief in their ability to succeed at a particular task or in a specific situation" and it is learned not inherited nor is it fixed and not generalizable but depends on a particular task or situation at hand [21].

With respect to sense of belonging [21] states self-efficacy is a necessary but not sufficient condition for persistence. It is also necessary the students in a way to feel as they used to feel in the previous educational environment that spent six years in high school. They must feel they are part of a (new) community of other students, faculty and staff who value them - that "they matter and belong" and even form Communities of Practice where sharing of knowledge is the central activity [25].

Students' perceptions of the value of their studies can also influence their motivation to persist. Although it is subject to debate as to what constitutes value if the student sees value in what he learns it can enhance motivation.

With respect to retention [26] identified four types of retention: institutional, system, academic discipline and course. The institutional retention is most commonly used by universities and deals with the percentage of students who return to the institution year after year. System retention consists of tracking of students who enroll at universities. Hagedorn [26] admits that this type is difficult to implement and costly. Retention within an academic major is focused on retaining the student in that disciple. Finally, course retention is similar to the academic discipline retention but focuses on retaining the student in that course. It is important though budgets are determined by the number of students in that course.

The institutional retention could cover the academic and course retention while system retention could be done by government. The institution though covers all costs and thus has to find a balance between retention at some cost or not allow a student to re-register. It has been argued by a number of authors [11],[27] that it is not the student that fails but it is the institution that fails to deliver its promise it made to the student and that is graduation. The institution should create early warning systems [21] as it was stated earlier, monitoring of progress, become engaged with the student to minimize the possibility of academic failure.

Ascend learning [28] promoted the idea of student data collection once the students are admitted and participating in the programme. This idea is necessary if we accept that factors of attrition can vary even between two adjacent provinces. The collected data are to be used by that individual institution for the next cohort. Ascend learning [28] suggests that at the onset, assessments can be used to help differentiate students that are likely to be successful from those that are likely to be unsuccessful based on students' level of preparedness for a particular programme [29]. Using performance on assessments together with other admissions criteria (e.g. previous courses taken, grade point average or previous work experience), can assist to define the population of students admitted into a program of that particular institution, which can impact student attrition [5]. Collecting data about student characteristics, their interactions with the course and other peers and faculty can assist also in identifying students at-risk [14]. One can learn so much about the students and how they learn (learning styles), collaboration with others, even personal factors that could affect their studies and render a hand. Furthermore collecting data also on subject specific concepts the students are struggling can assist the teacher to design supplementary materials for the new cohort. Giannakopoulos [30] used script analysis to identify the types of knowledge that students lack of. But even if students decide to leave, it is possible to have a kind of exit interviews so that reasons for leaving can be established. Glossop [31] found such data could result in great improvement in quantity and quality of information [14] and for comparison with other studies.

However, to design such systems it is also a matter of economics. Giannakopoulos [32] had suggested that it is possible to select a group of students and allow them to study for one year free. Then the successful ones to repeat the course and statistically speaking there will be a high pass rate and the prospect of graduating increases since most of the attrition occurs in the first year. To design such a system it will be extra cost to the institution but it will be once off expense which will be absorbed by the higher pass rate. This suggested path of 'first year free education' will be totally online which carries a minimum cost.

\section{B. Where to from here?}

Accepting attrition as a wicked problem then the question arises is: Should one concentrate decreasing attrition and by default costs will decrease and thus income will increase, or should one concentrate on decreasing costs? The two methods although they might achieve the same result require different approaches. Aljohani [33] states, reducing attrition costs is both educationally effective (more students obtain degrees) and cost effective (due to efficiency gains resulting from reduced attrition). For example a 20 percent reduction in attrition will increase degree or certificate production by 6 percent [5],[33]. In situations like these the two methods have to run parallel in a coordinated manner. Cost effectiveness should be a rule for any business in order to sustain itself. 
The moral side of higher education is that everybody should be given the chance to receive a higher education qualification but it must be accepted that higher education is a risky and expensive enterprise, as stated above, and therefore it must get return on its investment else it cannot sustain itself. Money has to come from somewhere. No matter which way we look at it is about money, economics in general, the production, consumption and transfer of wealth be it in form materials or knowledge. Therefore accessing education without success for any stakeholder of education it can only lead to a 'group of losers'. Graduating within the prescribed period it leads to a 'group of winners'.

Summarising the above exposition on access, attrition, retention and persistence, the four main constructs, the wickedness of the attrition " is highlighted by the student's typical problematic non predictive behaviour. The student wants to access free higher education. However about $50 \%$ dropout for numerous reasons. Academic failure only accounts for about $15 \%$ of the costs while at least $40 \%$ of the costs are from high achievers that dropout [33]. How can a student be so eager to access free higher education and dropout for reasons other than academic failure? It is the remaining $45 \%$ of the costs that spread over a number of factors which are unpredictable. It is not about accessing higher education, it is about economics.

\section{RECOMMENDATIONS FOR DECREASING ATTRITION AND MINIMISING COSTS}

The following recommendations are made in view of decreasing attrition and minimising the costs in higher education. Giannakopoulos [34] recommendation that admission to studies should be a three stage process, should be used to eliminate a number of barriers to graduation: Diagnostic testing followed by career counselling and aptitude testing for the particular field of study should precede registration [35]. Research [2],[21] has shown that self-efficacy, choosing the wrong course [9],[5] and not having the prerequisite knowledge for a particular subject are barriers to graduation. These three phases contain a certain extra cost to the institution which can be recovered from the decrease in attrition. It is not a popular way among the accountants but that cost should be seen as an investment. The cost could minimise as the years go by since most of the tuition testing could be fully online.

For an ODL [5] suggested (see Table I) the following:

Angelino, Williams, and Natvig [5] ideas concur with numerous other authors [27],[28],[33] ideas. The four points can be seen as parts of student engagement and use of online pedagogy. A number of other actions to be taken can be added to [5] recommendations.

- Hold an orientation day in the campus or campuses if the institution has branches. It is known as a first year experience (FYE). Tinto [2] and others [5],[22],[27] placed great importance on such day since it is about welcoming and orientation of the student. Tinto had gone as far as to suggest a full school term as an orientation phase.

- Contact students that did not submit the first assignment by phone preferably and record the reasons. Knowing why students do not submit assignments could be used to take proactive measures with the next cohort.

TABLE I: STRATEGIES TO DECREASE ATTRITION [5]

\begin{tabular}{ll}
\hline \multicolumn{1}{c}{ Strategy } & \multicolumn{1}{c}{ Rationale } \\
\hline $\begin{array}{l}\text { Student Integration and } \\
\text { Engagement }\end{array}$ & \\
$\begin{array}{l}\text { - Initiate contact with student via } \\
\text { phone call. }\end{array}$ & $\begin{array}{l}\text { Early and frequent contact with } \\
\text { students is critical. }\end{array}$ \\
- Conduct a pre-course & - Establishes a foundation for the \\
orientation. & $\begin{array}{l}\text { learning environment for all students. } \\
\text { Assess each student's pre-existing } \\
\text { knowledge, cultural perspectives, and } \\
\text { comfort level with technology to be }\end{array}$ \\
& $\begin{array}{l}\text { used in class. } \\
\text { - Facilitate informal online chats }\end{array}$ \\
through the course website. & interactions among students and \\
& faculty that may build positive \\
relationships and the foundation for & learning communities.
\end{tabular}

Learner-centered approach

- Begin courses with "Virtual

Icebreakers" to stimulate

communication.

- Post your introduction and encourage students to post their introduction.

- Opens the lines of communication with students as early as possible.

- Allows all participants an opportunity to learn more about each other (student to student and instructor to student).

Learning communities

- Develop group projects and assignments that encourage students to develop relationships with other members of the learning community so together they can explore existing knowledge and expand their knowledge base together.

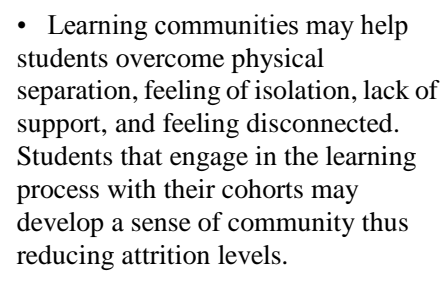
students overcome physical separation, feeling of isolation, lack of support, and feeling disconnected. Students that engage in the learning process with their cohorts may develop a sense of community thus reducing attrition levels.

Online Student Services

- Provide online access to a variety of services including assessments, educational counseling, registration, technical support, study skills assistance, career counseling, library services, students' rights and responsibilities, and governance. - Student government meetings on campus should be made available in electronic format.

- Focuses on the learner's needs; not just, what is easy. Online students may have similar needs for assistance and resources as traditional students.

- Provides distance education
students an opportunity to participate
in student governance as traditional
students.

- The suggested learning communities by [5] could be replaced by Communities of Practice (CoPs), where knowledge sharing for a common goal is the main characteristic of a CoP [25].

- The lecturer should become a Diagnostic Action Researcher (DAR) as suggested by [35]. Solomon [36] states that diagnosis is more than assessment as [36] puts it. For Solomon [36] a diagnostic teacher is the one who casts oneself as an observer, scrutiniser, and assessor, as well as an engaged teacher."

- Student monitoring of his/ her progress is another important action that should be implemented by the lecturer.

- It is customary in an ODL institution that for semester 
course two or three long assignments are given of or five to eight long assignments for a year course. What is suggested here is that a number of short assignments should be given and fewer long ones so that the student submits an assignment every second week and the assignment to be a continuous revision of the work.

- Use of tutors to assist students can also contribute to student engagement [5].

Although the above recommendations could contribute to the decrease in attrition, implementation and engaging the student is not a simple task. Data collected from Unisa's Learning Management System (LMS) in a first year course in computing indicate that on the average less than $10 \%$ of the students participate on online discussions. Non-participation by the student has been signaled at faculty meetings time and time again. But this is beyond this paper's objective. More research is necessary to establish why students do not engage in discussions and other activities aimed at assisting student to succeed.

\section{CONCLUSION}

Accessing higher education, even by most academically capable students, rich or poor, the road to graduation is not easy. Students, either dropout for unpredictable reasons or take much longer to complete their studies and thus there is no obvious solution, as it became a wicket problem. In both cases it is a loss for all stakeholders. Research has shown that an engaged student is more likely to persist and graduate while the institution using cost effective retention policies can contribute to student's persistence. It is not about accessing higher education as much as it is about economics. Higher education is a risky and expensive business for both the student and the institution. Both take chances. The former believing that he/ she has what it takes to graduate, the latter uses whatever means to allow students that are likely to graduate. Graduation or attrition are about pure economics. Either making profits (the institution has a healthy bank balance, the graduated student improves on his financial standing), or making losses. A balance between the two is necessary.

\section{REFERENCES}

[1] J. Bean, "Dropouts and turnover: The synthesis and test of a causal model of student attrition," Research in Higher Education, vol. 12, no. 2, pp. 155-187, 1980.

[2] V. Tinto, Leaving college: Rethinking the causes and cures of student attrition, 2nd ed.

[3] Chicago, University of Chicago Press, 1993

[4] A.W. Astin, What matters in college? Four critical years revisited, San Francisco, Jossey- bass inc, 1993.

[5] P. Prinsloo, "Modelling throughput at Unisa: A key to successful implementation of ODL," Pretoria, Unisa, DISA, 2009.

[6] L.M. Angelino, F.K. Williams, and D. Natvig, "Strategies to Engage Online Students and Reduce Attrition Rates," The Journal of Educators Online, vol. 4, no. 2, pp. 1-14, July 2007.

[7] S. Carr, "As distance education comes of age, the challenge is keeping the students," Chronicle of Higher Education, vol. 46, no. 23, A39-A41, 2000

[8] C. Beer and C. Lawson, "The problem of student attrition in higher education: An alternative perspective." Available at: http://dx.doi.org/10.1080/0309877X.2016.1177171 [10/02/2017, 2017], 2016
[9] H.W.J. Rittel and M.M. Webber, "Dilemmas in a General Theory of Planning," Policy Sciences. [Online]. 4, pp 155-169. Available: doi:10.1007/bf01405730.

[10] M.B. Paulsen, R.K. Toutkoushian, "Economic Models and Policy Analysis in Higher Education:A Diagrammatic Exposition," [Online] Available http://www.springer.cpm/chapter/10.1007/978-1-4020-69598_1,

[11] N. Raisman, "The Cost of College Attrition at Four-Year Colleges and Universities", Policy perspectives, The Educational Policy Institute, 2013

[12] J. Moody, "Distance education: Why are the attrition rates so high?" The Quarterly Review of Diatance Education, vol. 5, no. 3, pp 205-210, 2004.

[13] M. Blythman and S. Orr. 2002. A joined-up policy approach to student support. In Failing students in higher education, Eds. M. Peelo and T. Wareham, Buckingham, SRHE and Open University press, 2002

[14] J. Roberts and R. Styron, "Student Satisfaction and Persistence: Factors vital to persistence," Research in Higher Education Journal.

[15] C. Gillis, "Leaving Seats Empty: Exploring Student Attrition in an Undergraduate Health Sciences Program," Mount Saint Vincent University, 2007

[16] A. Giannakopoulos and S.B. Buckley, "Accessing Higher education," [Online]. Available: http://www.uj.ac.za/EN/Faculties/management/departments/bit/research /Documents/SB\%20-\%20Accessing\%20higher\%20education_FacultyM anagementConference.pdf.

[17] F. Newman, J. Couturier, and J. Scurry, The future of higher education. San Francisco, Jossey-Bass inc, 2004.

[18] L. Archer, C. Leathwood, and M. Hutchings, "Higher education: a risky business," in Access, participation and higher education: Policy and practice. A. Hayton and A. Paczuska, Eds. London, Biddles Ltd, 2002.

[19] T.H. Friedman, The world is flat. New York, Farrar, Straus and Giroux, 2005.

[20] S.B. Buckley and A. Giannakopoulos, "Sustainability of Open Distance eLearning institutions as knowledge producers: A theoretical perspective," presented at the 15th European Conference on Knowledge Management - ECKM 2014, Portugal, Polytechnic Institute of Santarém, September 4-5, 2014.

[21] A. Hayton and A. Paczuska, Eds. Access, participation and higher education: Policy and practice, London, Biddles Ltd, 2002.

[22] V. Tinto, "From retention to persistence," [Online] Available at: https://www.insidehighered.com>views.

[23] E.T. Pascarela and P.T. Terenzini, "How college affects students," vol. 2. A decade of research. San Francisco, John Wiley \& Sons, Inc, 2005.

[24] M. Martinez, "High attrition rate in e-learning: Challenges, predictors, and solutions," The eLearning Developers Journal, pp. 1-7, July 14, 2003

[25] Center for.. Center for the Study of College Student Retention. (n.d.). Retention definitions. Retrieved January 29, 2007, Available at: http://www.cscsr.org/retention_issues_definitions.htm

[26] A. Giannakopoulos, "Should we be Teaching or Diagnosing? An eLearning Paradox," presented at ICEPSS 2017 conference, Hiyas ng Bulacan Convention Center, Malolos City, Bulacan, Philippines, June 1-3, 2017.

[27] L.S. Hegedorn, "How to define retention: A new look at an old problem," in College student retention, A. Seidman, Ed. Westport, Praeger Publishers. 2005, pp. 89-105

[28] Ascend Learning, LLC, "Student attrition: Consequences, contributing factors, and remedies," March 2012.

[29] Assessment Technologies Institute (ATI), "Is the TEAS V predictive of early nursing school success?" [Online] Available at: www.atitesting.com.

[30] A. Giannakopoulos, "Programming: A wicked problem?" presented at SACLA 2017, Valley Lodge Magaliesburg, South Africa, July 3-7 2017.

[31] C. Glossop, "Student nurse attrition from pre-registration courses: investigating methodological issues," Nurse Education Today, vol. 21, no. 3 , pp. 170-180.

[32] A. Giannakopoulos, "Should we be Teaching or Diagnosing? An eLearning Paradox,"presented at ICEPSS 2017 conference, Hiyas ng Bulacan Convention Center, Malolos City, Bulacan, Philippines, June 1-3 2017

[33] O. Aljohani, "A Review of the Contemporary International Literature on Student Retention in Higher Education," International Journal of Education \& Literacy Studies,vol. 4, no. 1, January 2016. 
[34] A. Giannakopoulos, "Accessing Higher Education: A Right or a Privilege? A South African Open Distance Learning Pragmatic Dilemma," Presented at HELTASA conference, Pretoria, November 27-29 2013.

[35] A. Giannakopoulos, "The role of the educator in an open distance learning environment in the 21st century: Human versus machine? A pragmatic approach," presented at the 15th Annual conference on World Wide Web applications, CPUT, Cape Town, South Africa, September 11-13 2013.

[36] Solomon, M.Z. 1999. The diagnostic teacher: Constructing new approaches to professional development, NY, Teachers College Press.

[37] J. Wellman, N. Johnson, and P. Steele, "Measuring (and Managing) the Invisible Costs of Postsecondary Attrition", American Institute for research, Washington DC, September 2012. 